\title{
REFLEXÕES SOBRE O TREINAMENTO DO ATOR NA CONTEMPORANEIDADE: IMPACTOS DOS CONCEITOS DE CONTROLE, DISCIPLINA E BRICOLAGEM ${ }^{1}$
}

\author{
Henrique Bezerra de Souza \\ Professor da Universidade Federal de Santa Catarina, \\ doutorando em teatro pela Universidade do Estado de Santa Catarina, ator e diretor teatral \\ henriquebezerrads@gmail.com \\ José Ronaldo Faleiro \\ Professor titular da Universidade do Estado de Santa Catarina. \\ Doutor em Arts du Spectacle pela Université de Paris X - Nanterre (1998) \\ jrfalei@gmail.com
}

O presente artigo parte das questões que surgiram no trajeto artístico de um dos pesquisadores e visa refletir sobre a prática de treinamento de atores em obras cênicas contemporâneas, contaminadas cada vez mais por aspectos performativos. Para tanto, toma como base a aproximação que a pesquisadora Maria Brígida de Miranda realiza entre treinamento de atores e a ideia de disciplinas proposta por Michel Foucault. A partir da relação proposta, esta investigação busca ampliar a reflexão ao aproximar o treinamento de atores na contemporaneidade à ideia de Gilles Deleuze sobre a "sociedade de controle". Tal processo converge para uma investigação sobre os impactos que a transição do ideal de "sociedade disciplinar" para "sociedade controle" pode gerar no encaminhamento dos treinamentos. Por fim, defende-se a proposta que o treinamento de atores na contemporaneidade tende a adquirir aspectos cada vez mais individuais e pode ser analisado e refletido por meio de um processo de bricolagem de técnicas distintas.

Palavras-chave

Treinamento. Ator. Formação. Contemporaneidade. Bricolagem.
This article born from the issues that rounds the artistic path of one of the researchers aims to reflect about the practice of actor's training in contemporary scenic works, increasingly contaminated by performative aspects. Therefore, initiates from the approach that the researcher Maria Brigida Miranda performs between actor's training and the idea of disciplines proposed by Michel Foucault. From the proposed relationship, this research seeks to expand the reflection to approach the training of actors in the contemporaneity to the idea of Gilles Deleuze on the "societies of control". This converges process for an investigation into the impact that the transition from the ideal of "disciplinary society" to "control society" can generate in the process of training. Finally, it defends the proposal that the actor's training in contemporary society tends to gain more and more individual aspects and can be analyzed and reflected through a process of bricolage of different techniques.

Keywords

Training. Actor. Formation. Contemporaneity. Bricolage.

1 Pelo fato da reflexão aqui proposta se basear na experiência prática vivida apenas por um destes pesquisadores, Henrique Bezerra, a escrita deste artigo priorizará o posicionamento em primeira pessoa. 
Em O Poder Simbólico, Bourdieu (1998, p. 19) escreveu que o homo academicus gosta do que está finalizado, um pintor acadêmico é aquele que mostra a obra completa e faz desaparecer de seu trabalho o registro das pinceladas. Essa é uma afirmação que não consigo corroborar. Somo a minha identidade acadêmica à outra tão processual quanto, a de artista. Se não me considerasse como um processo, se me visse como uma obra finalizada, bem... eu estaria morto.

Observo que nas artes performativas dificilmente se tem uma obra acabada. Por mais cristalizada que seja a cena ou espetáculo a ser analisado, existe um nível improvisacional, momentâneo e irrepetível em sua execução. Realizada e observada por indivíduos viventes e mutáveis, a obra dificilmente será idêntica, visto que ela ocorre nas relações estabelecidas entre a cena e o público. Apesar da possibilidade de ser reexecutada, tal fato faz com que a cena teatral não se repita exatamente da mesma forma e, assim como o rio e o homem de Heráclito ${ }^{1}$, só pode ser vista em sua completude durante o ato de sua execução, realizada em processo.

Adotar essa perspectiva suscita algumas questões. Primeiramente, apesar de reconhecer a importância dos principais métodos de treinamento de atores surgidos na década de sessenta para edificação do ofício do artista, quando a prática teatral passa a evidenciar cada vez mais sua característica relacional e performativa, tais treinamentos, ou melhor, a

1 Heráclito foi um filósofo pré-socrático conhecido principalmente por formular o problema da unidade permanente do ser frente à mutabilidade e transitoriedade das coisas. De acordo com seu pensamento, todas as coisas se movem e nada permanece imóvel, lógica que é defendida no aforisma: o mesmo homem não pode entrar no mesmo rio duas vezes, pois nem ele, nem o rio são mais os mesmos. Para mais informações sobre suas reflexões verificar em SOUZA (1996). própria ideia de um treinamento, ainda pode ser considerada válida? A proposta de uma preparação, um treinamento para um ato que se concretiza prioritariamente no momento de sua execução e nas relações que estabelece enquanto se realiza, não poderia limitar as potencialidades expressivas vindouras?

$\mathrm{Na}$ tentativa de refletir sobre essas questões, proponho-me a rever um pouco do percurso de minha prática, retraçando as rotas que trilhei e compõem esse processo que sou; mostrar as pinceladas desse quadro em formação.

\section{A garrafa de café,} os rituais e as questões iniciais

Comecei a trabalhar com teatro em 2005 e meu primeiro contato veio por meio da universidade. Logo no primeiro ano, ingressei em uma companhia profissional de comédias ${ }^{2}$, na qual havia um fluxo constante de montagens teatrais. Fato que fez com que minha formação ocorresse no trânsito contínuo entre os muros da academia e as tábuas do palco.

$\mathrm{Na}$ faculdade de artes cênicas, tive contato com diversas formas de atuação, de treinamentos, dos quais os ideais que ainda ecoam na minha prática são compostos por pensamentos inspirados em Grotowski, Barba, Dario Fo e Stanislavski. A seriedade com que os professores e os encenadores tratados lidavam com o ofício teatral me encantava, e ainda encanta, de modo que concebi, em minha formação, que para ser um bom ator, deve-se

2 A Companhia Cearense de Molecagem foi fundada 1993 pelo ator e diretor Carri Costa, ela é reconhecida principalmente pelo seu repertório de comédias e paródias e trabalha desde então em sua sede no Teatro da Praia em Fortaleza $-\mathrm{CE}$. 
de fato realizar algum tipo de treinamento.

Todavia, concomitantemente a isso, vivia uma prática que parecia refutar esse pensamento. O discurso hegemônico dos atores mais antigos da "Companhia Cearense de Molecagem" via a ideia do treinamento como uma "romantização" acadêmica do ofício do ator. Para eles, a formação do artista cênico se dava exclusivamente na prática, no exercício de seu ofício. Nessa companhia, os ensaios se davam da seguinte forma: sentávamos todos à mesa onde tomávamos café juntos, conversávamos sobre assuntos corriqueiros, ríamos bastante, seguíamos para o palco do "Teatro da Praia" e passávamos a cena. Dificilmente havia algum tipo de alongamento, preparação corporal ou do espaço. A orientação era improvisar uma cena, com ou sem texto prévio, ou até mesmo seguir uma ideia já traçada pelo diretor. No fim, discutíamos sobre o que era interessante para o espetáculo em gestação, fixávamos e finalizávamos o ensaio.

Não havia propostas para intensificar a relação entre os atores, homogeneização do grupo, trabalho com conceitos da performance cênica como tensão/intenção, energia, nem mesmo exploração de ações desvinculadas da obra, trabalhávamos apenas em função de improvisos e repetições que visassem levantar uma cena. Se tivesse que afirmar que havia algum tipo de treinamento naquele momento, diria que era o improviso, o café e as conversas. Curiosamente, contrastando minhas crenças e práticas realizadas na academia, os espetáculos resultantes geralmente atingiam os objetivos a que se propunham.

No tempo que participei dessa companhia, convivi com artistas de diferentes gerações do teatro cearense. Apesar de não identificar um treinamento homogêneo entre nós, verificava que cada um tinha suas práticas particulares que realizava no cotidiano profissional e antes de entrar em cena. A maioria não reconhecia em seu discurso tais ações como treinamentos, apenas como "rituais pessoais para estar em cena". Tal fato incitava a seguinte questão: não seriam esses "rituais" formas de treinamentos pessoais? Carreguei essa pergunta durante os três anos em que fui ator da companhia, porém, na medida em que meus trabaIhos autorais exigiam mais tempo, desvinculeime do grupo e logo a esqueci.

Os espetáculos dos quais participei posteriormente já adotavam a ideia sobre treinamentos como bases para sua construção. Nesses processos, sempre havia uma preparação prévia na tentativa de homogeneizar o grupo, colocar o corpo dos atores em prontidão, bem como traçar estratégias de criação para as cenas. Cada proposta estética possuía assim uma forma de treinamento que lhe corroborasse, geralmente se afinando com algum dos encenadores citados no início desse artigo.

Contudo, apesar dos mais de dez anos investidos nas artes da cena, não houve treinamento com o qual me identificasse completamente. Minha prática foi e é permeada por um conjunto de escolhas, um conjunto de "rituais pessoais" que adotei para o ofício, aspectos que considerava importantes em cada experiência e, assim, moldei/estou moldando o que acredito ser importante para um ator em cena.

De início, esse processo pessoal de colagem me inquietava. Enquanto via companheiros se especializando na mímica corporal dramática de Étienne Decroux, outros se aprofundando nas ideias de Stanislavski e outros se tornando referência pelos estudos com a biomecânica de Meyerhold, eu era um híbrido. Não tinha a marca de um treinamento reconhecido em mi- 
nha prática como ator. Até o momento em que cheguei a me perguntar: isso é ruim? Até que ponto um tipo de treinamento é válido para um ator? Até onde ele não está contaminado pela estética que o gerou?

O prosseguimento de meu trabalho na cena, agora como diretor, só intensificou esses questionamentos. Assistindo e criando obras cada vez mais fragmentadas, desprovidas da centralização em torno de uma fábula, sem figuras ficcionais e não primando por uma hierarquia dos elementos cênicos, enfim, com aspectos cada vez mais performativos, problematizei ainda mais o papel do treinamento do ator. Em obras tão heterogêneas, que treinamento poderia auxiliá-lo em cena? Ou melhor, haveria um treinamento correto?

\section{Disciplina e controle} no treinamento de atores ${ }^{3}$

Na prática teatral, os paradoxos levantados por revisões estéticas tendem a perpassar o trabalho do ator, isso influencia o processo de formação, induzindo-o a não ser único e inequívoco, mas plural, fortemente ligado ao que se deseja que cumpra em cena. Esse vínculo é evidenciado quando se observa a ligação entre a prática do ator e as propostas diversas de encenação. Como defende Josette Féral, os estudos das formas de trabalho deste artista estão:

3 Já traçamos uma reflexão semelhante sobre o impacto dos conceitos de "disciplina" e "controle", porém, diferentemente deste artigo, tal reflexão não dava enfoque ao treinamento de atores mas sim à encenação. Este estudo pode ser encontrado no artigo "Em busca dos choques estéticos: a influência do controle na anestesia afetiva do espectador" na revista Urdimento, volume 2, n. 27, 2016.
[...] constantemente, para não dizer sempre, ligados a uma prática específica de teatro. As principais reformas da arte do ator foram pensadas no mesmo momento em que se deu a reformulação radical do teatro, quer se tratasse de Stanislavski, Meyerhold, Jouvet e Grotowski. (FÉRAL, 2010, p. 169).

Pensamento semelhante também pode ser encontrado em Burnier, quando o pesquisador afirma que "Toda expressão estética significa uma técnica." (BURNIER, 2009, p. 171) e até mesmo indiciado na seguinte questão que Grotowski responde: "Que tipo de exercícios eu deveria fazer? Depende da relação criativa de vocês com o teatro." (GROTOWSKI, 2010, p. 163). Com base nesses apontamentos, percebe-se que as necessidades estéticas tendem a exigir e gerar maneiras diferenciadas de formação do artista, porém, como isso ocorre nas práticas teatrais contemporâneas? Como se "pincela" o quadro desse artista?

Para responder a essa questão, é válido retomar um pouco a discussão sobre a ideia de treinamento. Em sua tese de doutorado, Maria Brígida de Miranda argumenta que a maioria dos métodos de treinamento do século XX introduziu uma disciplina que "[...] minou a liberdade física ao reproduzir grupos de corpos arregimentados e dóceis. Além disso, estes métodos procuraram moldar um tipo de corpo de ator para que, assim, fosse intercambiável entre outros atores". (MIRANDA, 2003, p. 10. Tradução minha). Segundo os pensamentos da autora, os métodos de treinamento desenvolvem práticas que, semelhante ao que Michel Foucault denominou como disciplinas, 
tendem a construir "corpos dóceis"4 na prática teatral. Em sua tese, a pesquisadora traça relações entre as tecnologias disciplinares ${ }^{5}$ de Foucault com os principais métodos de treinamento surgidos no século XX.

Acontece que, assim como defende Joseph Roach (1985), o teatro e sua prática estão conectados com outras instituições sociais. Ao relacionar a ideia de docilidade/utilidade apontada por Foucault na "sociedade disciplinar" com os treinamentos de atores, Miranda reforça essa conexão. Sob essa perspectiva se pode inferir que, por estar entranhada no berço social, a instituição teatral continua sofrendo mudanças. Como elas ecoam para o campo cênico?

Ora, Foucault já anunciava a brevidade da "sociedade disciplinar". Em uma conferência proferida no Japão, em 1978, o filósofo afirmou:

Nesses últimos anos, a sociedade mudou e os indivíduos também; eles são cada vez mais diversos, diferentes e independentes. Há cada vez mais categorias de pessoas que não estão

4 De acordo com Foucault, as disciplinas tendem a moldar o corpo dos homens em função de objetivos determinados, tal moldagem induz um processo de docilização que condiciona corpos dóceis. Em suas palavras: "O corpo humano entra numa maquinaria de poder que o esquadrinha, o desarticula e o recompõe. Uma "anatomia política", que é também igualmente uma "mecânica do poder", está nascendo; ela define como se pode ter domínio sobre o corpo dos outros, não simplesmente para que façam o que se quer, mas para que operem como se quer, com as técnicas, segundo a rapidez e a eficácia que se determina. A disciplina fabrica assim corpos submissos e exercitados, corpos "dóceis". (FOUCAULT, 1999, p. 164).

5 Foucault analisa os princípios de como as disciplinas agem para potencializar o caráter utilitário dos sujeitos ao mesmo tempo em que docilizam seus corpos. Neste processo, o filósofo identifica algumas práticas recorrentes como: a arte das distribuições, o controle da atividade, a organização das gêneses, a composição das forças, vigilância hierárquica, sanção normalizadora e o exame. Miranda reflete sobre como tais práticas podem estar inseridas no treinamento dos atores. Todavia, para não fugir do foco deste artigo, tal tópico não será desenvolvido. Para mais informações verificar Foucault (1999) e Miranda (2003). submetidas à disciplina, de tal forma que somos obrigados a pensar o desenvolvimento de uma sociedade sem disciplina. (FOUCAULT, 1978, p. 268)

$\mathrm{Na}$ visão do filósofo, as relações entre os homens sofreram a ação de forças e influências que colocavam a ideia das disciplinas em crise, ampliando as possibilidades de existência, rompendo modelos e anunciando outras propostas de mediação do poder. Gilles Deleuze, ao refletir sobre essas transformações, defende que o modo de interação das relações de poder tende a se distanciar da ideia da "sociedade disciplinar" e aponta o que ele chama de "sociedade de controle" (DELEUZE, 2008, p. 219). Para ele, as disciplinas apresentam moldes, enquanto o controle trabalharia com modulações. Em sua visão:

Os confinamentos são moldes, distintas moldagens, mas os controles são uma modulação, como uma moldagem auto-deformante que mudasse continuamente, a cada instante, ou como uma peneira cujas malhas mudassem de um ponto a outro. (DELEUZE, 2008, p. 221)

Essa transição enfraquece a noção de identidades fixas. Enquanto as disciplinas almejam a docilização dos corpos e dos seres, promovendo formas de subjetivação mais "sólidas" dos sujeitos (o operário, estudante, prisioneiro...), o controle traz a ideia de uma aparente flexibilidade. Tal situação não implica necessariamente em um desaparecimento das disciplinas ou dos modelos, mas, na contemporaneidade, tais propostas deixam de ser delimitadas somente por instituições reguladoras fixas (como a escola, hospital e prisão apontados por Foucault) e passam a ser criadas, disseminadas e construídas em várias esferas do campo social. 
Esse processo ocorre de maneira contínua através de ideais de comportamento constantemente impostos e veiculados pelas mídias, redes sociais, marketing das empresas, etc. No capitalismo contemporâneo, até mesmo as transgressões aos modelos não são necessariamente punidas, mas, ao invés disso, podem ser cooptadas, criando assim novos produtos, públicos e serviços que são capitalizados e rapidamente absorvidos pelo ideal do controle.

Nessa ótica, a aparente flexibilidade presente na proposta do controle carrega a possibilidade de ecoar para a instituição teatral na forma de estéticas mais fragmentadas e, com isso, passa a exigir uma reflexão sobre as posturas adotadas no treinamento do ator. Afinal, a construção de um corpo ideal traz forte consonância com a proposta disciplinar - na medida em que induz a construção de corpos corretos e docilizados para o fazer teatral - mas parece não contemplar a proposição do controle. Ao retomar as reflexões de Miranda, pode-se observar que:

No contexto do treinamento teatral a questão é se a subjetividade do professor de teatro e/ou diretor, ou seja, a pessoa que observa, é perpetuada neste processo de análise por meio da reprodução das próprias fisicalidades. [...] Nas sessões de treinamento de Decroux, os alunos não são instruídos apenas em uma maneira de execução, mas também em uma forma de "ver". Assim, no treinamento de Decroux, não é só uma fisicalidade específica que é encarnada, mas uma forma de enxergar a fisicalidade dos outros também é incorporada. Pode-se sugerir que esta fisicalidade e maneira de ver são cobradas pela própria fisicalidade e perspectiva de Decroux. Isto cria a necessidade de futuras discussões sobre os efeitos do treinamento físico nas identidades culturais e de gênero dos atores. (MIRANDA, 2003, p. 80-1. Tradução minha).
Ora, apesar de a autora adotar como exemplo o treinamento de Decroux, a questão apontada pode ser ampliada para outras esferas. Até que ponto o treinamento físico não condiciona modos de subjetivação específicos para os sujeitos? De acordo com Sonia Mansano (2009), a formação da identidade do indivíduo ocorre em constante processo de diálogo entre os estímulos que o meio social oferece e o modo singular como esses afetam o sujeito, ou seja, entre a sua subjetividade e os modos de subjetivação que são impostos. Esse processo é contínuo e retroalimentado, na medida em que o sujeito, ao apropriar-se dos componentes de subjetivação em circulação, passa também a emiti-los. Assim, os componentes se mantém em trânsito e são atualizados nessas relações, promovendo diferentes maneiras de ser no cotidiano de cada sujeito. Porém, há sempre o risco desses modos de subjetivação serem capturados e passarem a ditar um modelo que venha a suprimir as subjetividades dos indivíduos. Nas palavras da autora:

Diversas são as tentativas que tentam fixar a força subjetiva produtiva e dar-lhe uma determinada direção. Ao tomar uma posição dominante e organizada, a reprodução desses componentes desqualifica aquelas ações que colocam a vida em movimento. (MANSANO, 2009, p. 111).

Sob essa ótica, ao estabelecer formas específicas de "ver" e fisicalidades ideais, o treinamento de atores parece incorrer nesse risco e alimenta a construção de "identidades sólidas" para os artistas que, por sua vez, trazem poucas semelhanças com as "moldagens auto-deformantes" do ideal do controle e o processo de pluralização estética nas poéticas teatrais. Não obstante, o processo de docili- 
zação dos corpos tende a retirar uma parcela da força política ${ }^{6}$, fato que parece ir a contraponto das propostas cênicas contemporâneas que visam explorar a materialidade e o cunho político do teatro e dos corpos dos atores. Então, na contemporaneidade, não haveria treinamento?

\section{A bricolagem como} caminho ou ouroboros

Ora, mesmo em propostas mais fragmentadas o artista ainda lida com o manejo de energias da cena e dos espectadores ${ }^{7}$. Tal situação não implica necessariamente em uma negação da ideia de treinamento, mas em uma flexibilização desse processo. Ao invés de se submeter a um estilo específico e à construção de um corpo ideal/dócil, talvez um caminho possível seja a edificação da própria maneira de treinar. Uma atitude do ator que faça com que ele encontre o que é adequado para sua prática. Essa postura se afina com a aparente flexibili-

6 Ainda sob a ótica da docilização dos corpos, Foucault aponta como a disciplina molda o corpo do sujeito em favor de desígnios específicos, promovendo estratégias que aumentem a eficácia no alcance destes desígnios, mas, concomitantemente, impõem-Ihe formas de dominação. Em suas palavras: "A disciplina aumenta as forças do corpo (em termos econômicos de utilidade) e diminui essas mesmas forças (em termos políticos de obediência). Em uma palavra: ela dissocia o poder do corpo; faz dele por um lado uma "aptidão", uma "capacidade" que ela procura aumentar; e inverte por outro lado a energia, a potência que poderia resultar disso, e faz dela uma relação de sujeição estrita. Se a exploração econômica separa a força e o produto do trabalho, digamos que a coerção disciplinar estabelece no corpo o elo coercitivo entre uma aptidão aumentada e uma dominação acentuada." (FOUCAULT, 1999, p. 165)

7 Questões que podem ser vistas nos pensamentos de Lyotard, Féral, Lehmann e Cohen. Como exemplo, o fato do artista lidar: "[...] com o 'aqui-agora' e ter um contato direto com o público faz com que o trabalho com energia ganhe grande significação. Essa energia diz respeito à capacidade de mobilização do público para estabelecer um fluxo de contacto [sic] com o artista." (COHEN, 2007, p. 105). zação que se vê hoje no campo social e passa a incorporar diversas formas de proposições cênicas, não submetendo o artista a uma estética predominante. Afinal, observando as reflexões de Matteo Bonfitto, nota-se que:

[...] cada sistema de atuação permite o levantamento de uma série limitada de problemas durante o processo de criação de um espetáculo. O sistema concebido por Brecht, por exemplo, não é capaz de responder as questões que são implícitas no sistema grotóvskiano; da mesma forma o sistema de Stanislavski não responderá aquelas geradas pelas formulações de Artaud, etc. (BONFITTO, 2009, p. 40)

Sendo assim, visando aprofundar a reflexão sobre o treinamento, seria interessante indagar quais as questões que a cena contemporânea impõe ao ator? Levantar essa questão me parece um anacronismo, na medida em que a prática teatral passa a propor corporeidades, subjetividades diversas e intercambiáveis, não apenas identidades sólidas, interrompidas e disciplinares. Buscar uma resposta única e generalizante para essa pergunta provavelmente não seria produtivo e simplificaria a complexidade das propostas cênicas que vêm surgindo. No entanto, o que se pode entrever são respostas particulares e individuais dadas na relação que cada ator estabelecerá com os desafios impostos nas cenas. Tal ato pode proporcionar inclusive a adoção de procedimentos e técnicas de treinamento já existentes, porém sua utilização não é realizada necessariamente para o alcance de seu objetivo original, mas sim por meio de uma maneira na qual auxiliem o ator a alcançar os próprios objetivos.

Assim, a reflexão aqui proposta sobre a possibilidade de treinamento de atores na contemporaneidade não visa à negação de mes- 
tres ou técnicas, mas sim à construção da própria maneira de atuação que, à primeira vista, pode possuir pontos de confluência com um processo complexo de bricolagem. Tal ideia é inspirada no pensamento do antropólogo Claude Lèvi-Strauss, que defende que a bricolagem consiste na criação de um objeto novo a partir de fragmentos de outros objetos. Tais fragmentos pertencem a materiais que foram construídos para outros fins, porém o praticante, ou bricoleur, agora os remonta conforme a necessidade. Na visão do antropólogo, o primeiro passo desse praticante é:

\section{[...] retrospectivo, ele deve voltar para um conjunto já constituído, formado por utensílios e materiais, fazer ou refazer seu inventário, enfim, sobretudo, entabular uma espécie de diálogo com ele, para listar, an- tes de escolher entre elas, as res- postas possíveis que 0 conjunto pode oferecer ao problema coloca- do. (LÈVI-STRAUSS, 2011, p. 35) (Gri- fo nosso).}

Nesse viés, por meio do processo de bricolagem, o ator tira proveito apenas dos aspectos que lhe interessam dos estudos e reflexões acerca de seu ofício como um todo, aproveitando apenas os "fragmentos" úteis à sua prática individual. Assim, o ator contemporâneo continua atrelado à ideia de treinamento, mas amplia seus modos de construção, de modo que cada artista construirá, através da bricolagem o treinamento que considerará ideal para si, a própria resposta "ao problema colocado". Tal postura pode indicar um retorno do poder político ao corpo dos atores e o início de um desmantelamento da docilização deles, visto que o treinamento passa a ser construído no transcorrer da prática, nas intersecções, negações e criações de sistemas. Fato que carrega uma maior consonância com as reflexões e a "pluralização subjetiva" da "sociedade de controle".

A junção de elementos de fontes diversas não se limita a um encaminhamento prático do trabalho do ator, mas carrega a possibilidade de lançar luz às questões que provavelmente não viriam à tona caso tal aproximação não fosse realizada. Em certo sentido, as práticas que a bricolagem de treinamentos pode moldar são maiores do que a simples soma de seus componentes. Essa postura incentiva novos olhares sobre o trabalho do ator, reativa questões que porventura ficaram esquecidas no processo de edificação dos treinamentos cênicos e intercambia o pensamento de fontes distintas. Nessa ótica, as reflexões sobre a bricolagem de Joe Kincheloe e Kathleen Berry (2007) podem auxiliar a ilustrar o processo. $\mathrm{Na}$ opinião dos autores:

\begin{abstract}
À medida que, envolvendo-se no trabalho limítrofe da interdisciplinaridade profunda, os bricoleurs exploram aquilo que é descartado, encoberto, eles trazem à superfície os dispositivos ideológicos que apagaram os mundos e as experiências concretas dos que vivem à margem do poder. [...] ao empregar as dimensões metodológica, teórica, interpretativa, política e narrativa da bricolagem, os pesquisadores tornam visíveis uma série de traços anteriormente reprimidos do mundo social. (KINCHELOE, BERRY; 2007, p. 35)
\end{abstract}

Na medida em que a prática da bricolagem não trabalha apenas com a adoção de métodos consagrados para responder o problema que lhe é apresentado, mas a partir do problema, passa a intercambiar procedimentos de fontes diversas para a criação de algo que auxilie o questionador a encontrar a própria resposta, favorece então a criação de outros pontos de vista, "[...] novas visões sobre o caos 
da contemporaneidade [e] os pesquisadores se tornam mais bem equipados para imaginar para onde vamos e que caminho podemos tomar para cruzar a selva da informação que nos cerca" (KINCHELOE, BERRY; 2007, p. 36).

Entretanto, cabe salientar que a mera adoção positivista da colagem de métodos, práticas e exercícios oriundos de fontes diversas não condiz com a reflexão aqui engendrada. É recomendável que os atores/bricoleurs observem que seus materiais são provenientes de fontes diversas e não negligenciem a aura que os circundam (o que motivou seu desenvolvimento, anima sua existência, os aspectos culturais, etc.) mesmo que, por uma escolha consciente, eles neguem tais fatos. Nesse sentido, a prática da bricolagem e seu possível emprego no treinamento de atores propõemse a uma postura crítica e impele o seu praticante a tomar um posicionamento sobre como e quais materiais utiliza. Retomando os pensamentos de Kincheloe e Berry, vê-se que:

Os bricoleurs afirmam que a pesquisa empírica - na verdade, toda a pesquisa - é marcada em todos os níveis pelos seres humanos. Os pressupostos e, propósitos do pesquisador acabam sempre conseguindo se imiscuir em um ato de pesquisa, e sempre fazem diferença no conhecimento que é produzido. Mesmo nas formas mais prescritas de investigação quantitativa empírica, as preferências e os pressupostos do pesquisador determinam os resultados da pesquisa. [...] O caminho que se escolhe afeta profundamente aquilo que é encontrado. (KINCHELOE, BERRY; 2007, p. 20)

Dessa forma, pode-se entrever que o ato de bricolar comporta aspectos pessoais e relacionais, as escolhas não são feitas ao acaso, mas em consonância com o trajeto subjetivo do bricoleur. Esse é um dos aspectos cruciais para a reflexão sobre a bricolagem no treinamento de atores. A apropriação de métodos não ocorre de maneira estanque, mas através das relações que o ator estabelecerá com as propostas adotadas para o encaminhamento de sua prática.

Em certo sentido, a potência desse ato não está na anexação de procedimentos diversos visando à criação de uma forma de treinamento. De certa forma, tal postura já é comum no trabalho do ator ${ }^{8}$. Creio que a potência de pensar a bricolagem no treinamento de atores está nas fissuras que unem os procedimentos. Esses interstícios são preenchidos pelas relações subjetivas que cada ator entabula com os procedimentos escolhidos e o modo como eles passam a lhe fazer sentido. Desse modo, atores distintos podem bricolar exatamente os mesmos procedimentos de treinamento, mas a maneira como os rearranjam e preenchem as fissuras desta colagem poderá proporcionar encaminhamentos práticos bastante divergentes.

Assim, se os principais métodos de treinamento de atores do século XX, ao buscarem homogeneizar os sujeitos e produzir corpos ideais, docilizados, carregaram forte consonância com a construção de identidades fixas da "sociedade disciplinar"; o intercâmbio de técnicas e procedimentos de treinamento pro-

8 A adoção de práticas e exercícios oriundos de fontes distintas já é utilizada nas propostas de treinamento de atores. Tal ação não é em si inovadora e já foi praticada por diversos estudiosos do ofício cênico, tais como Grotowski que, no decorrer de suas fases, passou pela utilização de cantos haitianos, exercícios plásticos e as reflexões sobre ação física de Stanislavski; outro exemplo pode ser visto em Barba que observou manifestações espetaculares de fontes diversas para edificar seu treinamento com atores; ainda é possível citar Stanislavski, visto os constantes estudos que apontam suas relações com áreas distintas do conhecimento e, até mesmo, a influência do Yoga na edificação de seu sistema. Para mais informações sobre tais pontos, verificar respectivamente FLASZEN; POLLASTRELLI; MOLINARI (2010), BARBA (1994) e MAHFUZ (2014). 
duzidos pela bricolagem, ao evitar homogeneizar a subjetividade dos indivíduos e considerá-la no processo de construção pessoal da prática, pode favorecer a criação de uma pluralidade corporal e de formas de subjetivação que, por sua vez, apontam uma consonância com as tendências da cena contemporânea e a aparente flexibilidade da "sociedade de controle".

Contudo, entender a bricolagem como a solução para o treinamento do ator na contemporaneidade seria menosprezar a complexidade do processo cênico e do ofício do ator. Mesmo que sua prática favoreça a exploração de diversas formas de treinamento inspiradas nas questões individuais que motivam cada artista, é possível antever que, facilmente, um dos produtos da bricolagem possa ser cooptado pelo modelo do controle e passe a ditar um novo método de treinamento, corpos ideais para sua prática e, por consequência, subjetividades limitadas para o fazer teatral. Nessa perspectiva, a relação entre a bricolagem e o treinamento do ator carrega consigo a probabilidade de evocar a figura do ouroboros, ou seja, da serpente que morde a própria cauda. $\mathrm{Na}$ tentativa de fugir de modelos pré-estabelecidos, os artistas incorrem o risco de passar a ditar novos modelos.

Assim, o ato da bricolagem em si não é um caminho para o treinamento do ator na contemporaneidade, porém as reflexões que ele induz, como a tomada de uma postura crítica acerca dos métodos adotados e o fato de o artista tentar não suprimir a própria subjetividade em função de uma visão homogeneizadora, mas colocá-la em diálogo com as técnicas que utilizará em sua prática cênica, parece apontar os passos iniciais para uma reflexão a respeito do treinamento na contemporaneidade.
Justamente por levar tais aspectos em consideração, é recomendável que o ator tenha em mente que seu treino estará em constante mutação e repleto de características pessoais, podendo englobar práticas e "rituais pessoais" que lhe façam sentido.

Nessa ótica, diferente do "pintor acadêmico" abordado no início desse artigo, o treinamento do ator na contemporaneidade vive uma construção permanente, seu quadro nunca está finalizado e suas cores e desenhos podem ser compostos por pincéis de diferentes naturezas. Em meu caso, somo à minha prática as reflexões de Grotowski sobre impulso, tensão e intenção, a fisicalização do papel de Stanislavski, os estudos sobre energia de Barba, os pensamentos de Fo sobre o poder do gesto e o trabalho com as máscaras dell'arte, bem como as risadas, as conversas e o café que tomava nos anos iniciais de minha prática teatral.

\section{Referências}

BARBA, Eugenio. A canoa de papel: tratado de antropologia teatral. São Paulo: Hucitec, 1994.

BONFITTO, Matteo. A Cinética do invisível. São Paulo: Perspectiva, 2009.

BOUERDIEU, Pierre. O Poder Simbólico. Rio de Janeiro: Bertrand, 1998.

BURNIER, Luís Otávio. A arte de ator - da técnica à representação. Campinas: Unicamp, 2009.

COHEN, Renato. Performance como linguagem. São Paulo: Perspectiva, 2007. 
DELEUZE, Gilles. Conversações. Rio de Janeiro: ed. 34, 2008.

FÉRAL, Josette. A escola: um obstáculo necessário. Revista Ouvirouver, Uberlândia, n. 1, v. 6, p. $168-179,2010$.

FLASZEN, Ludwik; POLLASTRELLI, Carla; MOLINARI, Renata (orgs). O teatro laboratório de Jerzy Grotowski. 1959 - 1969. São Paulo: Perspectiva, 2010. p. 163-180

FOUCAULT, Michel. Vigiar e Punir: história da violência nas prisões. Petrópolis: Vozes, 1987.

A sociedade disciplinar em crise (1978). In: MOTA, Manoel Barros da (org). Ditos e escritos IV: estratégia, poder-saber. Rio de Janeiro: Forense Universitária, 2003.

GROTOWSKI, Jerzy. Exercícios. In: FLASZEN, Ludwik; POLLASTRELLI, Carla; MOLINARI, Renata (orgs). O teatro laboratório de Jerzy Grotowski. 1959 - 1969.São Paulo: Perspectiva, 2010. p. 163-180

KINCHELOE, Joe L; BERRY, Kathleen S. Pesquisa em educação: conceituando a bricolagem. Porto Alegre: Artmed. 2007.

LÉVI-STRAUSS, Claude. O pensamento selvagem. Campinas: Papirus, 1989.

MAHFUZ, Vicente. O Yoga no sistema de Konstantin Stanislávski: comunhão entre o espírito humano da personagem e o corpo humano do ator. 2014. 260f. Dissertação. (Mestrado em Teatro) - Centro de Artes, Universidade do Estado de Santa Catarina, Florianópolis, 2014.
MANSANO, Sonia. Sujeito, subjetividade e modos de subjetivação na contemporaneidade. Revista de psicologia da UNESP, São Paulo, n. 8, p. $110-117,2009$.

MIRANDA, Maria Brígida de. Playful training: towards capoeira in the physical training of actors. 2003. Tese. (Doutorado em Filosofia, Teatro e Drama) - School of Comunications, Arts and Critical Enquiry, Faculty of Humanities and Social Sciences, La Trobe University, Mellbourne, 2003.

$\mathrm{ROACH}$, Joseph. The Player's Passion: studies in the Science of acting. Newark: University of Delaware Press, 1985.

SOUZA, José Cavalcante de (org.). Os pensadores - Os Pré-Socráticos: fragmentos, doxografia e comentários. São Paulo: Nova Cultural, 1996.

Recebido: 31/08/2016 Aprovado: 16/12/2016 